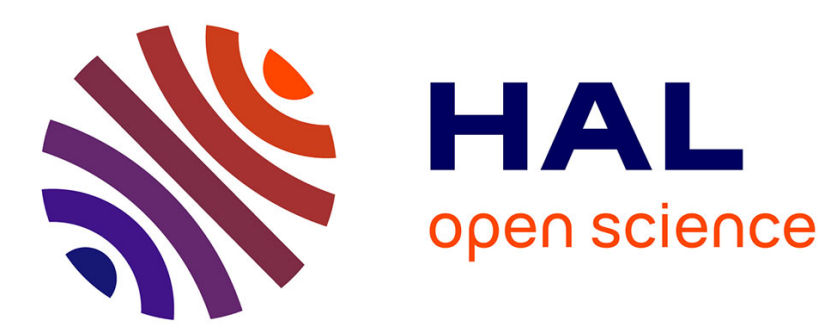

\title{
Label-free graphene oxide-based SPR genosensor for the quantification of microRNA21
}

\author{
Michael Michael Lopez Mujica, Yuanyuan Zhang, Fethi Bedioui, Fabiana \\ Gutierrez, Gustavo A. Rivas
}

\section{- To cite this version:}

Michael Michael Lopez Mujica, Yuanyuan Zhang, Fethi Bedioui, Fabiana Gutierrez, Gustavo A. Rivas. Label-free graphene oxide-based SPR genosensor for the quantification of microRNA21. Analytical and Bioanalytical Chemistry, 2020, 412, pp.3539-3546. hal-03021298

\section{HAL Id: hal-03021298 \\ https://hal.science/hal-03021298}

Submitted on 25 Nov 2020

HAL is a multi-disciplinary open access archive for the deposit and dissemination of scientific research documents, whether they are published or not. The documents may come from teaching and research institutions in France or abroad, or from public or private research centers.
L'archive ouverte pluridisciplinaire HAL, est destinée au dépôt et à la diffusion de documents scientifiques de niveau recherche, publiés ou non, émanant des établissements d'enseignement et de recherche français ou étrangers, des laboratoires publics ou privés. 
Label-free graphene oxide based-SPR genosensor for the quantification of

3 microRNA21

4 Michael López Mujica1, Yuanyuan Zhang², Féthi Bédioui2, ${ }^{*}$, Fabiana Gutiérrez ${ }^{1, *}$, 5 Gustavo Rivas ${ }^{1, *}$

$6 \quad{ }^{1}$ INFIQC-CONICET, Departamento de Fisicoquímica, Facultad de Ciencias

7 Químicas, Universidad Nacional de Córdoba, Ciudad Universitaria. 5000 Córdoba,

8 Argentina.

$9 \quad{ }^{2}$ Chimie ParisTech, PSL University, CNRS 2027, Institute of Chemistry for Life and 10 Health Sciences, SEISAD 75005 Paris, France.

11

12

$13{ }^{*}$ Corresponding authors:

14 Fabiana Gutierrez: fabigutierrez@gmail.com

15 Fethi Bedioui: fethi.bedioui@chimieparistech.psl.eu

16 Gustavo Rivas: grivas@fcq.unc.edu.ar 


\section{ABSTRACT}

19 This work is focused on the development of a genosensor for microRNA-21

20 quantification using Surface Plasmon Resonance (SPR) to transduce the

21 hybridization event. The biosensing platform was built by self-assembling two

22 bilayers of poly(diallyldimethylammonium chloride) (PDDA) and graphene oxide

23 (GO) at a gold surface modified with 3-mercaptopropane sulfonate (MPS), followed

24 by the covalent attachment of the DNA probe. GO was used in two directions, to

25 allow the anchoring of the probe DNA and to increase the sensitivity of the

26 biosensing event due to its field enhancer effect. The new bioanalytical platform

27 represents an interesting alternative for the label-free biosensing of microRNA-21,

28 with a linear range between $1.0 \mathrm{fM}$ and $10 \mathrm{nM}$, a sensitivity of $(5.1 \pm 0.1) \mathrm{m}^{\circ} \mathrm{M}^{-1}$ and a

29 detection limit of $0.3 \mathrm{fM}$. The proposed sensing strategy was successfully used for 30 the quantification of microRNA-21 in enriched urine samples.

31

32 KEYWORDS

33 microRNA-21; Genosensor; SPR; Graphene oxide; Cancer biomarker; Layer-by34 layer self-assembly.

35

\section{1. INTRODUCTION}

37 The microRNAs (miRNAs) are short endogenous and non-coding RNAs that 38 have an important effect on the expression of a large number of proteins and, 39 consequently on different molecular pathways [1]. They are present in several body 40 fluids, such as serum, blood, urine, saliva and tears, thereby enabling minimally 
41 invasive detection [2]. Since the dysregulation in microRNAs-expression is an initial

42 event in tumorigenesis, these microRNAs are very important biomarkers for early

43 diagnosis of cancer and represent a good promise to reduce the worldwide health

44 problem of this pathology [3, 4]. The advantages of miRNAs as biomarkers are

45 connected with their high stability, their presence in several biological materials and

46 the significant differences on their expression in healthy and pathological individuals

$47[5]$.

48 microRNA-21 is an oncogenic microRNA that has been connected with 49 different diseases, especially cancer. It has been found in patients with cervical 50 cancer and has demonstrated to be useful for the prognosis and therapeutic 51 application [6]. A critical study about the connection between dysregulated miRNAs 52 and prostate cancer showed that miRNA-21 is one of the four microRNAs that give 53 relevant information for the detection, prognosis and evaluation of the therapy [7]. 54 microRNA-21 is also involved in the growth, metastasis and apoptosis of non-small 55 cell lung cancer and is a promising biomarker for its diagnosis and prognosis [8]. 56 Kura et al. [9] also showed that some biologically active nutrients like 57 polyunsaturated fatty acids, vitamins $E$ and $D$, dietary fiber, or selenium affect the 58 expression of many miRNAs, connected with cardiovascular diseases, like miRNA$5921,-30$ family, $-34,-155$, or -199 .

60 The determination of miRNAs is very complex due to their short sequence, 61 low levels and high similarity between them. The current gold standard technique for 62 miRNA detection is quantitative real-time polymerase chainreaction ( $q P C R$ ) where

63 the quantification of miRNAs extracted from body fluids is achieved through reverse 
64 transcription of miRNA and labeling with fluorescent probes [10]. Other common

65 methods used in miRNA detection are surface enhanced Raman scattering,

66 microarrays and Northern blot [11-13]; however, they present important limitations

67 like requirement of specialized personnel and need of centralized laboratories with

68 expensive instrumentation [14]. Electrochemical biosensors have also demonstrated

69 to be a very useful tool for the sensitive and selective quantification of microRNAs

70 [15-17].

71 SPR biosensing strategies have made possible the real-time and label-free

72 detection of different bioanalytes, providing additional useful information about

73 binding kinetics and bioaffinity interactions. Q. Wang et al. [18] reported the selective

74 femtomolar SPR detection of microRNA-21 by taking advantage of the electronic

75 coupling between $\mathrm{Au}$ nanoparticles (AuNPs)-localized plasmon and Au surface

76 plasmon, and the refractive index enhancement of the medium next to $\mathrm{Au}$ film

77 caused by the hybrid generated between the DNA-linked AuNPs on the Au film

78 surface and the terminus of capture DNA. A similar strategy was proposed by Liu et

79 al. [19] for the sub-fM detection of microRNA-21 and cancer cells based on a multiple

80 signal amplification strategy using a thiol-modified hairpin probe immobilized on a

81 gold film with silver NPs deposited after the formation of the DNA supersandwich

82 structure. Xue et al. [20] reported the use of antimonene for the specific label-free

83 and aM detection of miRNA-21 and miRNA-155 due to the substantially stronger

84 interaction of antimonene with ssDNA compared to DNA-RNA heteroduplex and the

85 use of Au nanorods to amplify the SPR signal. Sipova et al. [21] presented a sensitive

86 miRNA quantification strategy using a high-performance portable SPR sensor for 
87 spectroscopy of surface plasmons based on a special diffraction grating

88 functionalized with the probe DNA and disperser (SPRCD) and the use of an

89 antibody able to recognize the DNA-RNA duplex. The sensor was used to quantify

90 miRNA from mouse liver tissues. Gayatri et al. [22] described a regenerative, solid-

91 state localized SPR (LSPR) sensor based on gold nanoprisms that circumvent the

92 need for labels or amplification, and enabled the detection of sub-fM microRNA-21

93 and microRNA-10b in human plasma of pancreatic cancer patients. SPR was also

94 used for the quantification of microRNA-10b at attomolar level [23] and microRNA-

9593 at picomolar level [24]. Feng et al. [25] reported a surface plasmon-enhanced

96 electrochemiluminescence with $\mathrm{Ag}$ nanoclusters deposited at DNA as

97 electrochemiluminiscence emitters and AuNPs deposited at glassy carbon electrode

98 (GCE) as localized surface plasmon resonance source in combination with a

99 catalytic hairpin assembly amplification that allowed to reach a detection limit of 0.96

100 aM and a successful determination of miRNA-21 in enriched diluted serum samples.

101 Here, we are proposing a bioanalytical platform for the detection of microRNA-

10221 with SPR transduction based on the use of a gold disk modified with 3103 mercaptopropane-1-sulfonate (MPS) followed by the self-assembling of 104 poly(diallyldimethylammonium) chloride (PDDA) and graphene oxide (GO) and the 105 covalent attachment of capture DNA. In the following sections we discuss the 106 influence of the number of PDDA/GO bilayers on the plasmonic response of the 107 resulting platform; the optimization of the amount of DNA probe immobilized at the 108 surface and the hybridization time on the detection of the hybridization event; and 109 the analytical performance of the biosensor. 


\section{MATERIALS AND METHODS}

\subsection{Chemicals and reagents}

Sodium 3-mercapto-1-propanesulfonate (MPS), N-hydroxysuccinimide

(NHS), Poly(diallyldimethylammonium chloride) (PDDA), N-(3-

116 dimethylaminopropyl)-N'-ethylcarbodiimide hydrochloride (EDC), ethanolamine (Et),

117 benzoquinone, hydroquinone, and poly(acrylic acid) (PAA) were purchased from

118 Sigma-Aldrich. Ethanol, sulfuric acid (98\%) and sodium hydroxide were provided by

119 J. T. Baker. Graphene oxide (GO) was obtained from Graphenea. Other chemicals were reagent grade and used without further purification. The DNA and RNA sequences (Invitrogen Life Technologies), are the following: miRNA-21: 5'-UAG-CUU-AUC-AGA-CUG-AUG-UUG-A-3' used for preparing all the solutions.

\subsection{Apparatus}

A platinum wire and $\mathrm{Ag} / \mathrm{AgCl}, 3 \mathrm{MNaCl}$ were used as counter and reference

131 electrodes, respectively. All potentials are referred to the latter. Electrochemical 132 Impedance Spectroscopy (EIS) measurements were performed with an Autolab 
PGSTAT30 potentiostat (Methrom). The experiments were carried out in a $0.050 \mathrm{M}$ phosphate buffer solution $\mathrm{pH} 7.40$, using $2.0 \times 10^{-3} \mathrm{M}$ benzoquinone/hydroquinone as redox indicators. The EIS parameters were the following, amplitude: $0.010 \mathrm{~V}$, frequency range: $1.0 \times 10^{-2}$ to $1.0 \times 10^{6} \mathrm{~Hz}$ and working potential: $0.200 \mathrm{~V}$. The impedance spectra were analyzed and fitted by using the Z-view program. Surface Plasmon Resonance (SPR) measurements were performed using a single channel Autolab E-SPR SPRINGLE instrument (Eco Chemie). A standard gold disk (BK-7 Eco Chemie), mounted on a hemicylindrical lens through indexmatching oil was used to build the platform. Sample solutions were injected manually and the measurements were carried out under batch conditions at $25^{\circ} \mathrm{C}$. The analytical signal was obtained from the change in the SPR minimum angle $\left(\Delta \theta_{\mathrm{SPR}}\right)$.

UV-Vis experiments were carried out with a Shimadzu UV1601 spectrophotometer and a quartz cuvette of $0.1 \mathrm{~cm}$ path length.

\subsection{Construction of the biosensing platform}

Figure 1 displays a scheme with the different steps during the construction of the biosensing platform. The gold disk was modified in-situ using a $2.00 \times 10^{-2}$ M MPS solution (prepared in $1.60 \times 10^{-3} \mathrm{M} \mathrm{H}_{2} \mathrm{SO}_{4}$ ) for $60 \mathrm{~min}$. After washing the surface, it was allowed to interact with PDDA $\left(1.00 \mathrm{mg} \mathrm{mL}^{-1}\right.$, prepared in $0.050 \mathrm{M}$ phosphate buffer solution $\mathrm{pH} 7.40)$ for $15 \mathrm{~min}$ and after that, with $\mathrm{GO}\left(0.50 \mathrm{mg} \mathrm{mL}^{-1} \mathrm{GO}\right.$ solution prepared in $0.10 \mathrm{M} \mathrm{NaOH}$ ) for $30 \mathrm{~min}$. This procedure was repeated twice to obtain the required platform Au/MPS/(PDDA/GO) 2 . The carboxylate residues of GO were activated with an EDC/NHS mixture $(0.100 \mathrm{M}$ prepared in $0.050 \mathrm{M}$ phosphate buffer 
156 solution $\mathrm{pH} 7.40$ ) for $20 \mathrm{~min}$ and after that it was allowed to interact with a $50 \mathrm{ppm}$

157 DNA probe solution (prepared in $0.050 \mathrm{M}$ phosphate buffer $\mathrm{pH} 7.40+0.500 \mathrm{M} \mathrm{NaCl}$ )

158 for $30 \mathrm{~min}$. The unreacted GO carboxylate groups were quenched by adding $1.0 \mathrm{M}$

159 Et solution $(\mathrm{pH}$ 8.30) for $15 \mathrm{~min}$. The hybridization event was performed at $160 \mathrm{Au} / \mathrm{MPS} /(\mathrm{PDDA} / \mathrm{GO})_{2} / \mathrm{DNA}$ by interacting with miRNA-21 (prepared in $0.050 \mathrm{M}$ 161 phosphate buffer solution $\mathrm{pH} 7.40+0.500 \mathrm{M} \mathrm{NaCl}$ ) for $120 \mathrm{~min}$. The surface of the 162 modified gold-disk was carefully washed between the different steps. In fact, it was 163 washed with the medium used to prepare the solution that interacted with the surface 164 in the previous step, and then, for three times, with the medium used to prepare the 165 solution that will interact with the platform in the next step. To obtain additional 166 information, the platform Au/MPS/(PDDA/GO) $)_{2}$ was also interrogated by EIS using 167 gold electrodes ( $\mathrm{CH}$ Instruments, $3 \mathrm{~mm}$ diameter) prepared under the same 168 experimental conditions as the SPR sensor.

169

170

\section{RESULTS AND DISCUSSION}

171 One interesting alternative to improve the sensitivity of SPR determinations is 172 the incorporation of plasmonic nanostructures to SPR substrates due to the coupled 173 field increments [26]. The high transmittance of the graphene-sheet and the high 174 confinement and propagation of the surface plasmonic polaritons make 175 graphenaceous materials very useful elements for the construction of SPR 176 biosensors [27-29]. Therefore, taking into account the importance of GO to improve 177 the sensitivity of SPR determinations, we evaluated the effect of the number of GO 
178 layers immobilized at the gold disk by EIS, through the variations of the total charge

179 transfer resistance $\left(R_{c t}\right)$, and by SPR, through the changes in the plasmon angle.

180 Figure $2 \mathrm{~A}$ shows the changes in the total $\mathrm{R}_{\mathrm{ct}}$ obtained after the assembling of 181 several layers of PDDA and GO at Au/MPS using hydroquinone/benzoquinone as 182 redox markers. The inset shows the Nyquist plots corresponding to the first two 183 PDDA/GO bilayers, where the circles are the experimental points and the solid lines 184 correspond to the fitting of these results with the equivalent circuit. The adsorption 185 of $\mathrm{GO}$ at Au/MPS/PDDA produces an increment in the $\mathrm{R}_{\mathrm{ct}}$ due to the poor 186 conductivity of GO. The assembling of the next layer of PDDA produced a new 187 increment in $\mathrm{R}_{\mathrm{ct}}$ due to the blockage effect, to increase even more after the 188 immobilization of the second layer of GO. Further immobilization of GO or PDDA 189 does not produce significant changes, indicating that after the second PDDA/GO 190 bilayer there is no substantial increment in the thickness of the multilayers system 191 due to a poor accumulation either of GO or PDDA. The system was fitted with a 192 double time constant equivalent circuit (also shown in the inset) based on the 193 capillary membrane model, which has been used to evaluate the charge transport 194 through multilayers of polyelectrolytes, to demonstrate the existence of possible 195 defects in these multilayers systems $[30,31]$. This model assumes that the electrode 196 is not fully covered during the construction of the supramolecular architecture 197 defining areas more accessible for the charge transfer of the redox mediator. The 198 Nyquist plots present wide semicircles, product of the combination of two time 199 constants, indicating the existence of areas with two different heterogeneous rate 200 constants for hydroquinone/benzoquinone charge transfer [32]. Therefore, the 
201 results presented in Figure 2A suggest that after the assembling of GO there is not

202 full coverage of the PDDA layer, with the consequent existence of regions with different GO coverage and incomplete charge reversion of PDDA.

The platform was also evaluated by SPR. Figure 2B depicts the changes in $\Delta \theta_{\mathrm{SPR}}$ during the assembling of the different PDDA and $\mathrm{GO}$ layers. $\Delta \theta_{\mathrm{SPR}}$ increases 206 after each immobilization step up to the second (PDDA/GO) bilayer, in agreement 207 with the EIS results, indicating that there is an effective immobilization of PDDA and 208 GO up to the second bilayer. Further adsorption of GO or PDDA produces almost no change in $\theta_{\mathrm{SPR}}$. Therefore, two (GO/PDDA) bilayers were selected as the 210 optimum platform for building the biosensor.

One of the main advantages of SPR-based biosensors is the capability to 212 follow in real time the different steps during the construction of the bioanalytical 213 platform and the detection of the biosensing event. Figure 3A shows the SPR profiles 214 obtained during the building of the whole bioanalytical platform 215 (Au/MPS/(PDDA/GO) $)_{2} / \mathrm{DNA}$ and the target recognition. The analytical signal in the 216 presence of microRNA-21 was obtained from the change in $\theta_{\text {SPR }}$ before and after 217 the target addition and rinsing with Tween + buffer solution (inset of Figure 3A). To 218 evaluate more clearly these changes, Figure 3B displays the increment of $\Delta \theta_{\mathrm{SPR}}$ after 219 the incorporation of each layer of the biosensing platform and after the hybridization with microRNA-21.

222 The SPR angle increases with the hybridization time from 60 to $120 \mathrm{~min}(13.9,20.9$ and $42.5 \mathrm{~m}^{\circ} \mathrm{M}^{-1}$ for 60,90 and $120 \mathrm{~min}$, respectively) and we selected $120 \mathrm{~min}$ as 
224 the best compromise between assay time and sensitivity. The effect of the amount 225 of DNA probe covalently attached at Au/MPS/(PDDA/GO $)_{2}$ through the EDC/NHS 226 chemistry, was also investigated by SPR. No significant changes in $\theta_{\mathrm{SPR}}$ were 227 observed for 50,100 and 300 ppm DNA probe; therefore, we selected 50 ppm for 228 further work. To demonstrate the advantages of GO on the SPR response, we built 229 another supramolecular arquitecture by using PAA as negatively charged polymer 230 instead of GO. $\Delta \theta_{\mathrm{SPR}}$ increases during the assembling of the two (PDDA/PAA) 231 bilayers although after the covalent attachment of the DNA probe and further 232 hybridization with microRNA-21, the changes in the SPR angle were very small, 233 indicating that the presence of GO is really necessary to obtain a sensitive SPR 234 response (not shown).

236 3.3. Analytical performance of the genosensor

Figure $4 \mathrm{~A}$ displays the plot of $\Delta \theta_{\mathrm{SPR}}$ as a function of microRNA-21 238 concentration. There is a linear dependence between $1.0 \mathrm{fM}$ and $10 \mathrm{nM}$, with a 239 sensitivity of $(5.1 \pm 0.1) \mathrm{m}^{\circ} \mathrm{M}^{-1}$ and a detection limit of $0.3 \mathrm{fM}$ (calculated as $3 \times \mathrm{SD} / \mathrm{s}$ 240 where SD is the standard deviation of the blank signal and s, the sensitivity). The 241 reproducibility, obtained from the determination of $10^{-10} \mathrm{M}$ with three different 242 biosensors was $5.8 \%$. Table 1 compares the analytical characteristics of our 243 biosensor with the most relevant SPR-based microRNA-21 biosensors reported in 244 the last years. The bioanalytical platform reported here presents detection limits 245 lower or comparable to most of the biosensors reported in the table and higher than 246 the one obtained using an amplification signal based on the use of antimonene and 
247 AuNRs [20]. Therefore, the proposed strategy demonstrated to be competitive 248 compared to the SPR-based microRNA21 biosensors already reported since it 249 presents very good analytical performance using a simple scheme without the need 250 of amplification steps. The selectivity of the biosensor was examined through the 251 interaction of the biosensor with two non-complementary sequences, a fully non252 complementary one and a one-base mismatch sequence. The response of the 253 biosensor in both cases is considerably smaller than the one for microRNA-21. In 254 fact, the analytical signal for the fully non-complementary was $0 \%$ while for a one255 base mismatched sequence, it was only $40 \%$ of the one obtained in the presence of microRNA-21.

To evaluate the usefulness of Au/MPS/(PDDA/GO) 2 /DNA biosensing platform for further analytical applications, we quantify microRNA-21 in a 1:10 diluted urine sample enriched with $1.0 \times 10^{-10} \mathrm{M}$ microRNA-21, being the recovery 91.3 and 87.0

$260 \%$. These results indicate that the proposed biosensor could be used for practical 261 applications.

\section{CONCLUSIONS}

In summary, we reported a SPR biosensor for the femtomolar quantification of microRNA-21 using a simple scheme based on a supramolecular architecture built at a thiolated gold platform containing GO with successful application for the

267 quantification of microRNA-21 in enriched urine samples. The incorporation of GO

268 in the multistructure facilitates the covalent attachment of the $\mathrm{NH}_{2}-\mathrm{DNA}$ probe and

269 makes possible the enhancement of the SPR analytical signal, eliminating, in this 
270 way, the need for additional amplification scheme. The proposed strategy opens the

271 door to the development of other biosensors by anchoring the corresponding

272 biorecognition molecule at Au/MPS/(PDDA/GO)

273

274 ACKNOWLEDGEMENTS

275 Financial support from CONICET, ANPCyT, SECyT-UNC (Argentina) and ECOS-

276 SUD program (A16E02). M. L.-M. thankfully acknowledges CONICET for the PhD

277 fellowship. Y. Zhang thanks Chinese Scholarchip Council for providing a three-year

278 scholarship for her stay in France and LabEx MICHEM for supporting her living 279 expenses in UNC Argentina.

280

281 DECLARATION OF CONFLICT OF INTEREST

282 No authors have any conflicts of interest to disclose.

283

\section{REFERENCES}

285 1. Mazunder S, Datta S, Ray JG, Chaudhuri K, Chateerjee R. Liquid biopsy: miRNA as a potential biomarker in oral cancer. Cancer Epidemiol. $2019 ; 58: 137-145$

2. C.-S. Zhu CS, Zhu L, Tan DA, Qiu XY, Liu CY, Xie S, Zhu LT. Avenues Toward microRNA Detection In Vitro: A Review of Technical Advances and Challenges Comput. Struct. Biotechnol. J. 2019;17:904-916.

3. Hayes J, Peruzzi PP, Lawler S. MicroRNAs in cancer: biomarkers, functions and therapy. Trends in Molecular Medicine. 2014;20:460-469. 
293 4. Shajari E, Mollasalehi H. Ribonucleic-acid-biomarker candidates for earlyphase group detection of common cancers. Genomics. 2020;112:163-168.

5. Peng $\mathrm{Y}$, Croce $\mathrm{CM}$. The role of MicroRNAs in human cancer. Signal Transduct. Target. Ther. 2016;1:15004.

6. Hasanzadeh M, Movahedi M, Rejali M, Maleki F, Ahmadi MM, Seifi S, Hosseini Z, Khazaei M, Amerizadeh F, Ferns GA, Rezayi M, Avan A. The potential prognostic and therapeutic application of tissue and circulating microRNAs in cervical cancer. J Cell Physiol. 2019;234:1289-1294.

7. Sharma N, Baruah MM. The microRNA signatures: aberrantly expressed miRNAs in prostate cancer. Clin Transl Oncol. 2019;21:126-144.

8. Zheng W, Zhao J, Tao Y, Guo M, Ya Z, Chen C, Qin N, Zheng J, Luo J, L, Xu 304 L. MicroRNA-21: A promising biomarker for the prognosis and diagnosis of non-small cell lung cancer. Oncology Letters. 2018;16:2777-2782.

9. Kura B, Parikh M, Slezak J, Pierce GN. The Influence of Diet on MicroRNAs that Impact Cardiovascular Disease. Molecules 2019;24:1509.

10. Varkonyi-Gasic E, Wu R, Wood M, Walton EF, Hellens RP. Protocol: a highly sensitive RT-PCR method for detection and quantification of microRNAs. Plant Methods 2007;3:12.

11. Várallyay E, Burgyán J, Havelda Z. MicroRNA detection by northern blotting using locked nucleic acid probes. Nat. Protoc. 2008;3:190.

313 12. Lee I, Ajay SS, Chen H, Maruyama A, Wang N, Mclnnis MG, Athey BD. 314 Discriminating single-base difference miRNA expressions using microarray Probe Design Guru (ProDeG). Nucleic Acids Res. 2008;36:e27. 
316 13. Li P, Long F, Chen W, Chen J, Chu PK, Wang H. Raman scattering, Fundamentals and applications of surface-enhancedRaman spectroscopybased biosensors. Current Opinion in Biomedical Engineering. 2020;13:5159.

14. Liu L, Song C, Zhang Z, Yang J, Zhou L, Zhang X, Xie GG. Ultrasensitive electrochemical detection of microRNA-21 combining layered nanostructure of oxidized single-walled carbon nanotubes and nanodiamonds by hybridization chain reaction. Biosens. Bioelectron. 2015;70:351-357.

15. Kutluk $H$, Bruch $R$, Urban GA, Dincer $C$. Impact of assay format on miRNA sensing electrochemical microfluidic biosensors for miRNA-197 detection. Biosensors and Bioelectronics. 2020;148:111824.

16. Zouari M, Campuzano S, Pingarron JM, Raouafi N. Femtomolar direct voltammetric determination of circulating miRNAs in sera of cancer patients using an enzymeless biosensor. Analytica Chimica Acta. 2020 (in press).

17. Jirakova L, Hrstka R, Campuzano S, Pingarron J, Bartosik M. Multiplexed immunosensing platform coupled to hybridization chain reaction for electrochemical determination of microRNAs in clinical samples. Electroanalysis. 2019;31:293-302. resonance biosensor for enzyme-free amplified microRNA detection based on gold nanoparticles and DNA supersandwich. Sensors and Actuators B. 2016;223:613-620. 
19. Liu R, Wang Q, Li Q, Yang X, Wang K, Nie W. Surface plasmon resonance biosensor for sensitive detection of microRNA and cancer cell using multiple signal amplification strategy. Biosensors and Bioelectronics. 2017;87:433438.

20. Xue T, Liang W, Li Y, Sun Y, Xiang Y, Zhang Y, Dai Z, Duo Y, Wu L, Qi K, Shivananju BN, Zhang L, Cui X, Zhang H, Bao Q. Ultrasensitive detection of miRNA with an antimonene-based surface plasmon resonance sensor. Nature Communications. (2019);10:1.

21. Sıpova H, Zhang S, Dudley AM, Galas D, Wang K, Homola J. Surface Plasmon Resonance Biosensor for Rapid Label-Free Detection of Microribonucleic Acid at Subfemtomole Level. Anal. Chem. 2010:82:1011010115.

22. Joshi GK, Deitz-McElyea S, Johnson M, Mali S, Korc M, Sardar R. Highly Specific Plasmonic Biosensors for Ultrasensitive MicroRNA Detection in Plasma from Pancreatic Cancer Patients. Nano Lett. 2014;14:6955-6963.

23. Joshi GK, Deitz-McElyea S, Liyanage T, Lawrence K, Mali S, Sardar R, Korc M. Label-Free Nanoplasmonic-Based Short Noncoding RNA Sensing at Attomolar Concentrations Allows for Quantitative and Highly Specific Assay of MicroRNA-10b in Biological Fluids and Circulating Exosomes. ACS Nano. 2015;9:11075-11089.

24. Schmieder S, Weißpflog J, Danz N, Klotzbach U, Sonntag F. Detection of 359 miRNA using a surface plasmon resonance biosensor and antibody 360 amplification. Current Directions in Biomedical Engineering. 2016;2:135-138. 
361 25. Feng X, Han T, Xiong Y, Wang S, Dai T. J. Chen, X. Zhang, G. Wang. Plasmon-Enhanced Electrochemiluminescence of Silver Nanoclusters for microRNA Detection. ACS Sens. 2019;4:1633-1640.

26. Zeng S, Baillargeat D, Ho HP, Yong KT. Nanomaterials enhanced surface plasmon resonance for biological and chemical sensing applications Chem. Soc. Rev. 2014;43:3426-3452.

27. Grigorenko AN, Polini M, Novoselov KS. Graphene plasmonics. Nat. Photonics 6 (2012) 749-758.

28.Jung I, Rhyee JS, Son JY, Ruoff RS, Rhee KY. Nanotechnology. 2012;23:25708-25716.

29. Primo E, Kogan M, Verdejo H, Bollo S, Rubianes MD, Rivas G. Label-Free Graphene Oxide-Based Surface Plasmon Resonance Immunosensor for the Quantification of Galectin-3, a Novel Cardiac Biomarker. ACS Applied Materials and Interfaces. 2018;10:23501-23508.

30. Barreira SVP, Garcia-Morales V, Pereira CM, Manzanares JA, Silva F. Electrochemical Impedance Spectroscopy of Polyelectrolyte Multilayer Modified Electrodes. J. Phys. Chem. B. 2004;108:17973-17982.

31. Fernández-Sánchez C, McNeil CJ, Rawson K. Electrochemical impedance spectroscopy studies of polymer degradation: application to biosensor development. Trends Anal. Chem. 2005;24:37-48. 


\section{LEGENDS OF THE FIGURES}

Figure 1. Scheme for the different steps during the building of microRNA-21

genosensor at Au/MPS/(PDDA/GO) 2 platform.

391 Figure 2. A) Bars plot for the variation of total $R_{c t}$ during the self-assembling of 1.00 $\mathrm{mg} \mathrm{mL}^{-1}$ PDDA (red) and $0.50 \mathrm{mg} \mathrm{mL}^{-1} \mathrm{GO}$ (blue) at Au/MPS platform. The inset shows the Nyquist plots for the two layers of PDDA and two layers of GO as well as 394 the corresponding equivalent circuit. Redox marker: $2.0 \times 10^{-3} \mathrm{M}$ 395 hydroquinone/benzoquinone; EIS parameters: amplitude: $0.010 \mathrm{~V}$, frequency range: $3961.0 \times 10^{-2}$ to $1.0 \times 10^{6} \mathrm{~Hz}$; Working potential: $0.200 \mathrm{~V}$. B) $\Delta \theta_{\mathrm{SPR}}$ calculated from the 397 sensorgram obtained during the consecutive self-assembling of 4 bilayers of 1.00 $\mathrm{mg} \mathrm{mL}^{-1}$ PDDA (red) and $0.50 \mathrm{mg} \mathrm{mL}^{-1} \mathrm{GO}$ (blue). Rinsing solutions: $0.050 \mathrm{M}$ 399 phosphate buffer solution pH 7.40 before and after self-assembling of PDDA; and $400 \quad 0.100 \mathrm{M} \mathrm{NaOH}$ before and after the immobilization of GO.

401 402 Figure 3.A) SPR sensorgram obtained during the building of microRNA-21 403 genosensor: immobilization of MPS at Au (black arrow), PDDA at Au/MPS (red 404 arrow), GO at Au/MPS/PDDA (blue arrow), activation of Au/MPS/(PDDA/GO) $)_{2}$ with 405 EDC/NHS (green arrow), covalent attachment of DNA probe (pink arrow), quenching 
406 with Et (orange arrow), and interaction with microRNA-21 (violet arrow). The inset

407 shows the $\Delta \theta_{\text {SPR }}$ obtained after addition of microRNA-21, used as the analytical

408 signal. B) $\Delta \theta_{\mathrm{SPR}}$ calculated from the sensorgram obtained in A).

409

410 Figure 4. Calibration plot for microRNA-21 quantification. Each point is an average

411 of three different experiments.

412

413 


\section{LEGENDS OF THE FIGURES}

Figure 1. Scheme for the different steps during the building of microRNA-21 genosensor at Au/MPS/(PDDA/GO) 2 platform.

Figure 2. A) Bars plot for the variation of total $R_{c t}$ during the self-assembling of 1.00 $\mathrm{mg} \mathrm{mL}^{-1}$ PDDA (red) and $0.50 \mathrm{mg} \mathrm{mL}^{-1} \mathrm{GO}$ (blue) at Au/MPS platform. The inset shows the Nyquist plots for the two layers of PDDA and two layers of GO as well as the corresponding equivalent circuit. Redox marker: $2.0 \times 10^{-3} \mathrm{M}$ hydroquinone/benzoquinone; EIS parameters: amplitude: $0.010 \mathrm{~V}$, frequency range: $1.0 \times 10^{-2}$ to $1.0 \times 10^{6} \mathrm{~Hz}$; Working potential: $0.200 \mathrm{~V}$. B) $\Delta \theta_{\mathrm{SPR}}$ calculated from the sensorgram obtained during the consecutive self-assembling of 4 bilayers of 1.00 $\mathrm{mg} \mathrm{mL}^{-1}$ PDDA (red) and $0.50 \mathrm{mg} \mathrm{mL}^{-1} \mathrm{GO}$ (blue). Rinsing solutions: $0.050 \mathrm{M}$ phosphate buffer solution $\mathrm{pH} 7.40$ before and after self-assembling of PDDA; and $0.100 \mathrm{M} \mathrm{NaOH}$ before and after the immobilization of $\mathrm{GO}$.

Figure 3.A) SPR sensorgram obtained during the building of microRNA-21 genosensor: immobilization of MPS at Au (black arrow), PDDA at Au/MPS (red arrow), GO at Au/MPS/PDDA (blue arrow), activation of Au/MPS/(PDDA/GO) 2 with EDC/NHS (green arrow), covalent attachment of DNA probe (pink arrow), quenching with Et (orange arrow), and interaction with microRNA-21 (violet arrow). The inset shows the $\Delta \theta_{\mathrm{SPR}}$ obtained after addition of microRNA-21, used as the analytical signal. B) $\Delta \theta_{\mathrm{SPR}}$ calculated from the sensorgram obtained in A). 
Figure 4. Calibration plot for microRNA-21 quantification. Each point is an average of three different experiments. 


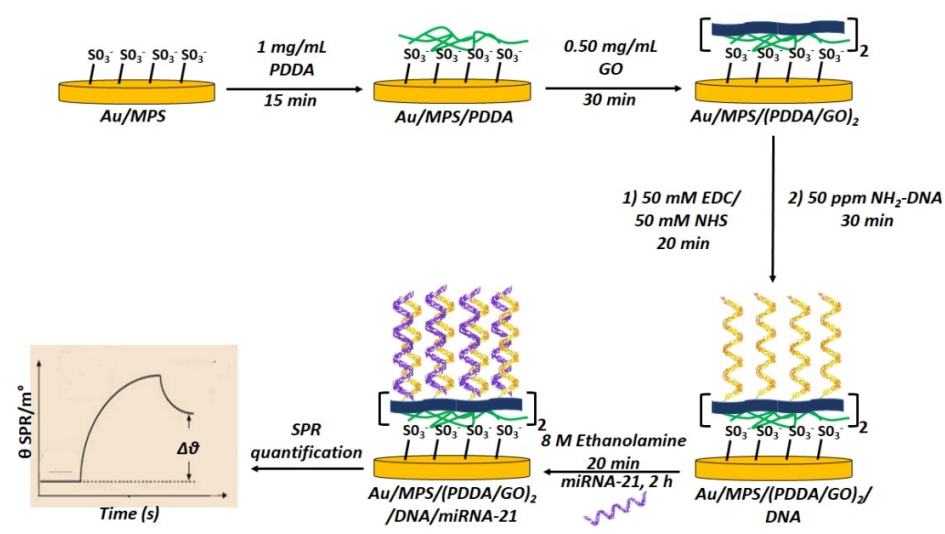




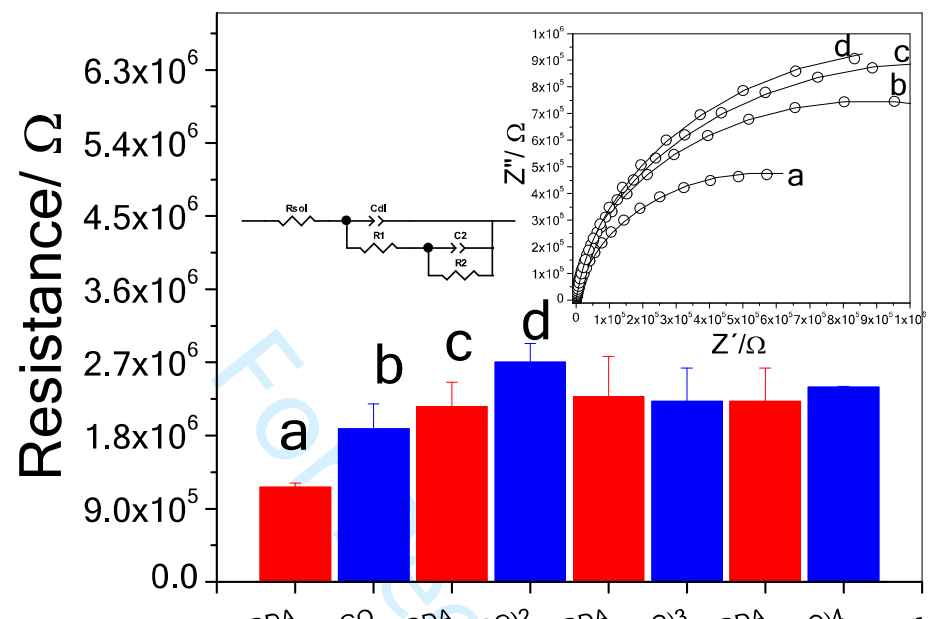
MPSIPDDA ADA-GO -PDDA -GO) 2 -PDDA $-G O)^{3}$ 3-PDDA $\left.-G O\right)^{4}$ MPSSIPDDA-MPSI (PPDDA-GMS-(PDDDA-GMS-(PDD)

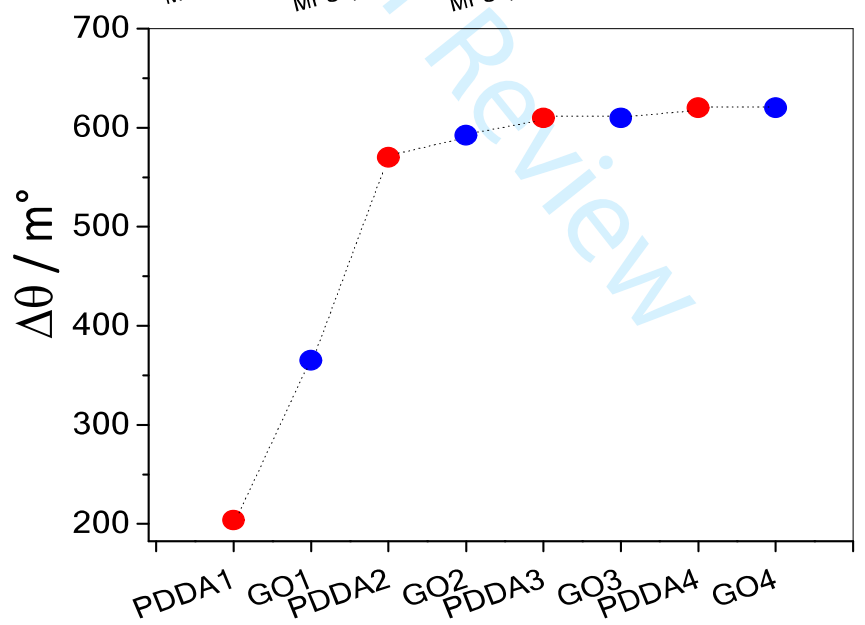

FIGURE 2-RIVAS ET AL. 


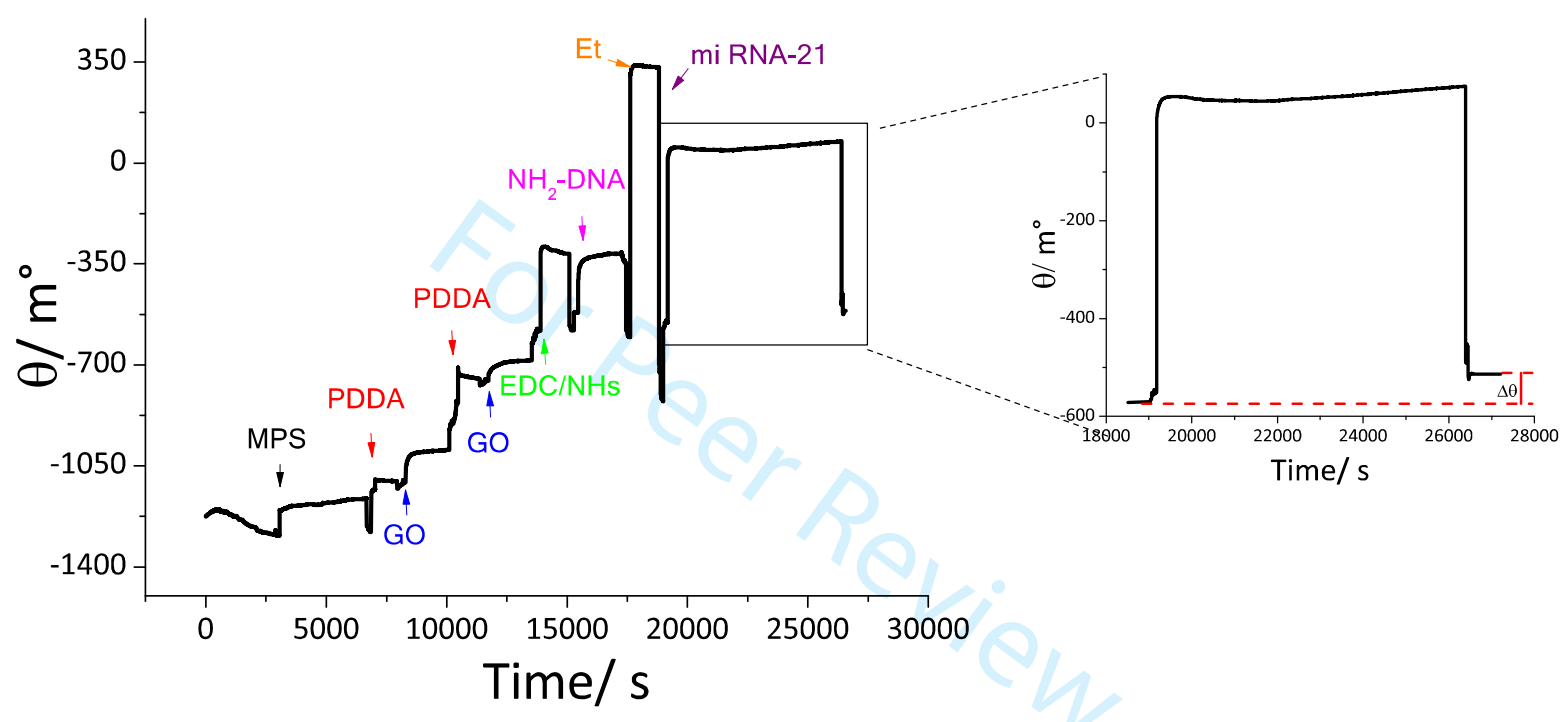

FIGURE 3A-RIVAS ET AL. 
Analytical \& Bioanalytical Chemistry

Page 6 of 53

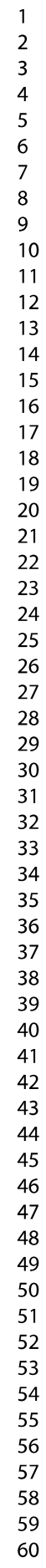

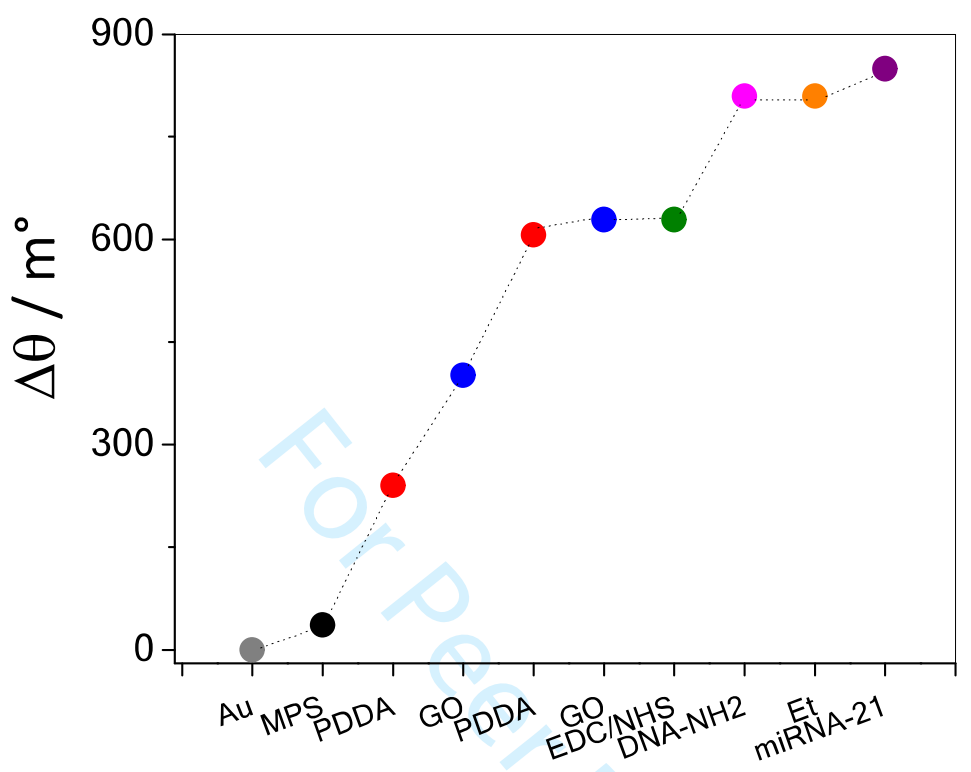

FIGURE 3B-RIVAS ET AL. 


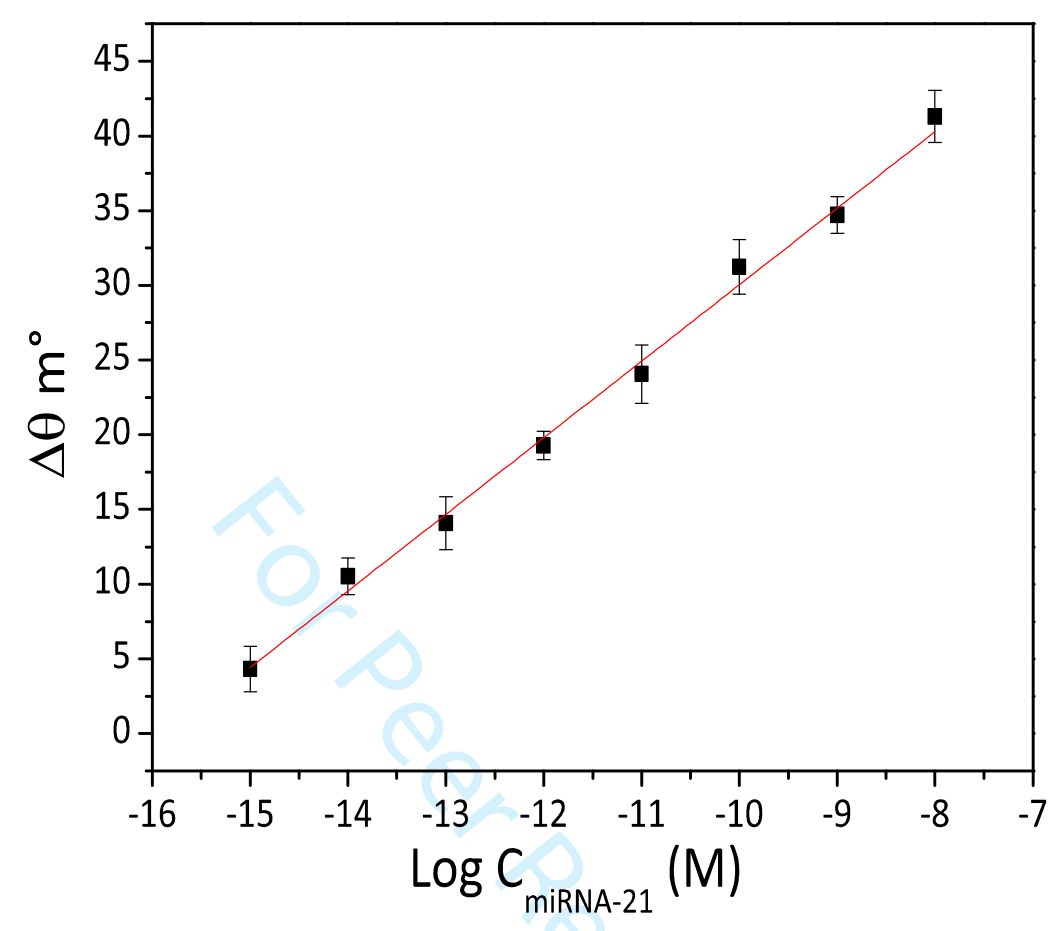

FIGURE 4-RIVAS ET AL 


\begin{tabular}{|c|c|c|c|c|c|c|}
\hline Target & $\begin{array}{l}\text { Technique } \\
\text { used for } \\
\text { detection }\end{array}$ & Signal amplification strategy & $\mathbf{D L}$ & $\begin{array}{c}\text { Linear range } \\
{[\mu \mathrm{M}]}\end{array}$ & Real sample & Ref. \\
\hline miRNA-21 & SPR & $\begin{array}{c}\text { gold nanoparticles (AuNPs) coupled } \\
\text { with DNA } \\
\text { supersandwich }\end{array}$ & $8 \mathrm{fM}$ & Up to $150 \mathrm{pM}$ & human serum & [18] \\
\hline miRNA-21 & SPR & $\begin{array}{c}\text { DNA-linked AuNPs, DNA } \\
\text { supersandwich structure and } \\
\text { positively charged silver nanoparticles } \\
\text { (AgNPs) }\end{array}$ & $0.6 \mathrm{fM}$ & Up to $10 \mathrm{pM}$ & - & [19] \\
\hline $\begin{array}{l}\text { miRNA-21 } \\
\text { miRNA-55 }\end{array}$ & SPR & $\begin{array}{l}\text { Au nanorods connected to amplify } \\
\text { SPR signal and antimonene for } \\
\text { discriminating ssDNA and DNA-RNA } \\
\text { heteroduplex }\end{array}$ & $10 \mathrm{aM}$ & $10^{-17}$ to $10^{-11} \mathrm{M}$ & - & {$[20]$} \\
\hline $\begin{array}{l}\text { miRNA-21 } \\
\text { miR-10b }\end{array}$ & LSPR & - & $\begin{array}{c}23-35 \\
\mathrm{fM}\end{array}$ & $0.01-100 \mathrm{nM}$ & plasma & [21] \\
\hline miRNA-21 & SPR & {$[\mathrm{PDDA}-\mathrm{GO}]_{2}$} & $0.3 \mathrm{fM}$ & $1.0 \times 10^{-15}$ to $1.0 \times 10^{-6} \mathrm{M}$ & urine & $\begin{array}{l}\text { This } \\
\text { work }\end{array}$ \\
\hline
\end{tabular}

solid-state localized surface plasmon resonance (LSPR)

TABLE 1-RIVAS ET AL. 


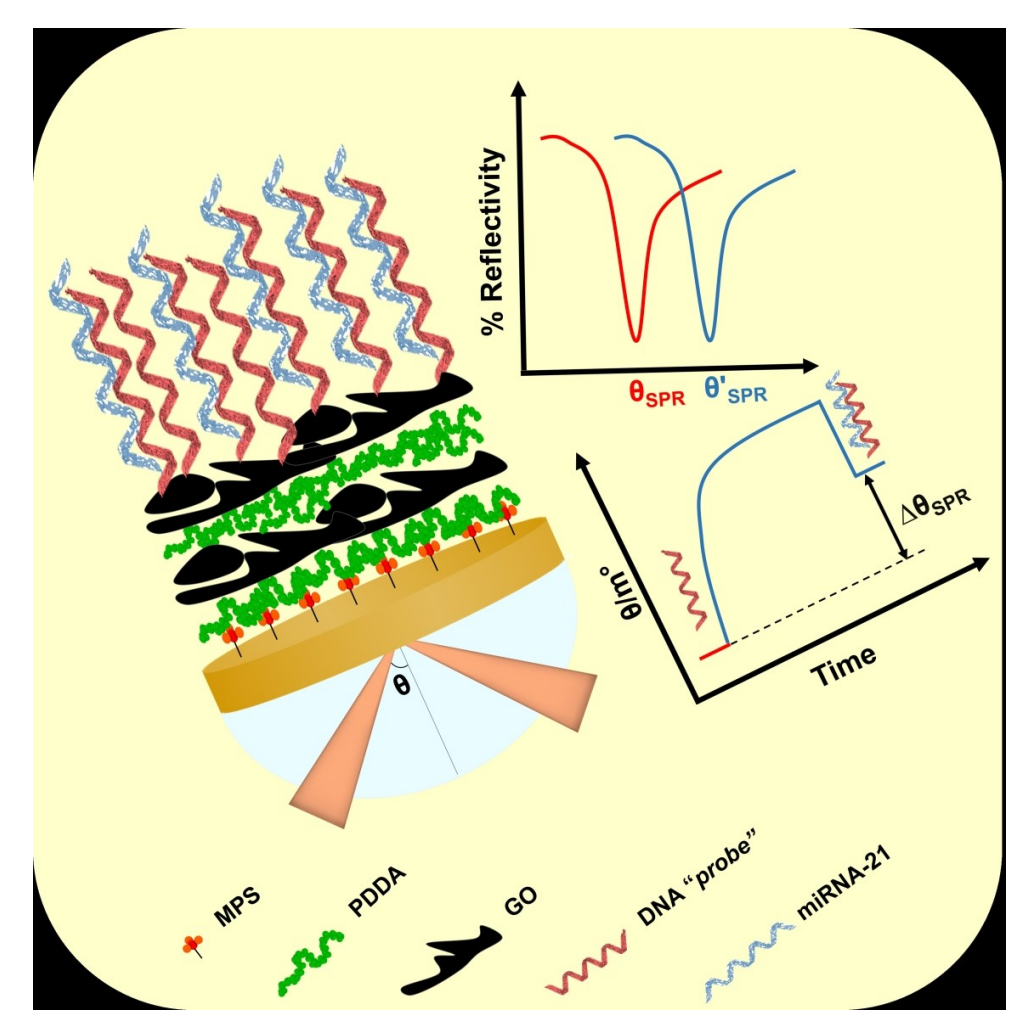




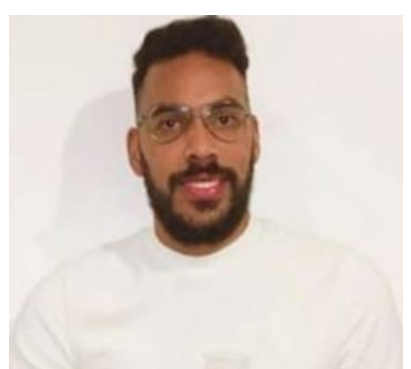

Michael LOPEZ MUJICA

obtained the Bachelor in Chemistry from Orient University. Currently, he is PhD student in the group of Biosensors at Physical Chemistry Department, Chemical Sciences Faculty, Cordoba National University (Argentina). His work is focused on the development of new biosensing strategies for the quantification of clinical biomarkers based on the use of nanomaterials.

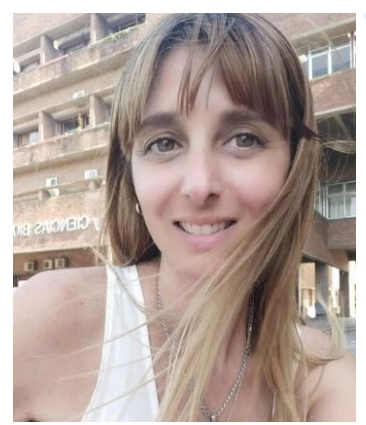

Fabiana GUTIERREZ

obtained her PhD from the Cordoba National University (Argentina). Currently, she is Researcher at Argentine Research Council (CONICET), Laboratory of Analytical Development and Chemometrics (LADAQ) Faculty of Biochemistry and Biological Sciences, Litoral National University (Santa Fe, Argentina). Her research interests focus on the development of impedimetric and plasmonics genosensors and immunosensors.

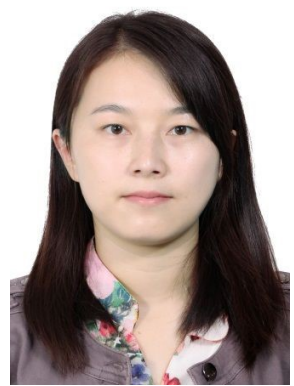

Yuanyuan ZHANG

is a $\mathrm{PhD}$ of the Equipe "Synthèse, Electrochimie, Imagerie et Systèmes Analytiques pour le Diagnostic" of Chimie ParisTech (Université Paris sciences et lettres - PSL) in Paris, France. She works on the detection method of the clinical biomarker microRNA. 


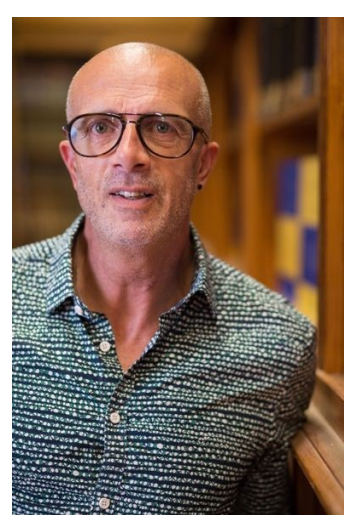

Fethi BEDIOUI

is Senior Researcher at CNRS working at ChimieParisTech-PSL (Institute of Chemistry for Life and Health Sciences).His current research interests revolve around the development and the implementation of advanced molecular materials for electrocatalysis and electrochemical sensing devices for biologically relevant molecules (thiols, nitric oxide, peroxynitrite etc.). His scientific work is reflected in over 260 publications including books and book chapters $(\mathrm{H}$ index $=51)$.

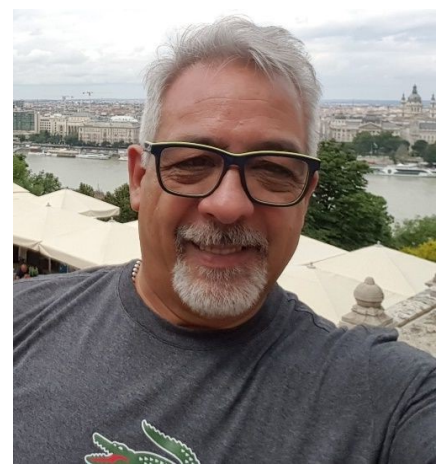

Gustavo RIVAS

is Plenary Full Professor at Chemical Sciences Faculty (FCQ), Cordoba National University (Argentina) and Superior Researcher at Argentine Research Council (INFIQC-CONICET). He is member of the National Academy of Sciences of Argentina and Co-Editor-in-Chief of Sensors and Actuators B: Chemical. He is author of more than 170 publications including book chapters, with more than 7500 citations and $\mathrm{H}$ index $=48$. He was President of the Argentinean Association of Analytical Chemists and Head of the Physical Chemistry Department (FCQ). His current research activities are focused on the development of enzymatic and affinity nano(bio)sensors devoted to the quantification of clinical and environmental relevant (bio)markers. 